\title{
DE QUEM É O CURRÍCULO? PROBLEMATIZAÇÕES POR UMA EDUCAÇÃO NÃO SOBERANA
}

\author{
Larissa Ferreira Rodrigues Gomes ${ }^{(*)}$ \\ Helder Januário da Silva Gomes ${ }^{(* *)}$
}

\section{INTRODUÇÃO: DE QUEM É O CURRÍCULO?}

Evocados pela problematização "De quem é a escola?”, proferida por uma estudante que subiu à tribuna da Assembleia Legislativa do Paraná (Alep) ${ }^{1}$, para defender a "Primavera Secundarista", ousamos indagar ainda mais: "De quem é o currículo?”.

Figura 1. Capa do Jornal Le Monde Brasil diplomatique, em destaque Primavera secundarista.

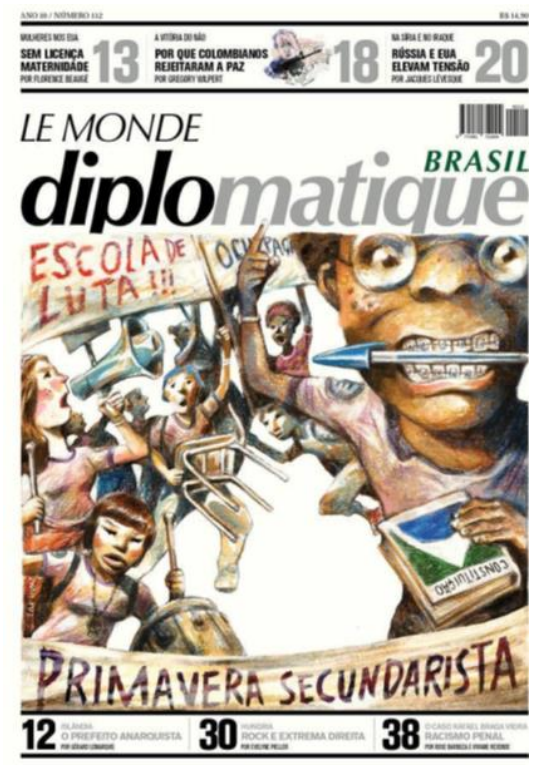

Fonte: 〈http://diplomatique.org.br/edicao-112/>. Acesso em: 22 set. 2017.

\footnotetext{
${ }^{(*)}$ Doutora em Educação pela Universidade Federal do Espírito Santo (UFES), professora da Educação Básica Técnica e Tecnológica na Universidade Federal do Espírito Santo (UFES), no Centro de Educação Infantil Criarte e professora do Programa de Pós-graduação de Mestrado Profissional em Educação (PPGMPE/UFES). Coordenadora do Grupo de pesquisa do CNPq Currículos, culturas juvenis e produção de subjetividades.

${ }^{(* *)}$ Mestrado em Ciências das Religiões (2012), pela Faculdade Unida. Atualmente é professor de geografia do Instituto Federal do Espírito Santo. Líder do Grupo de Pesquisa Currículos, culturas juvenis e produção de subjetividades (CNPq). Possui graduação em licenciatura plena em Geografia pela UFES (1999), pós-graduado em Geografia Humana e Produção do Espaço (2001) pela Pontifícia Universidade Católica de Minas Gerais PUC-Minas).

${ }^{1}$ A estudante Ana Julia Pires Ribeiro realizou o discurso em 26 de outubro de 2016 e participa da ocupação do Colégio Estadual Senador Manuel Alencar de Guimarães, em Curitiba - PR. 4 A Primavera Secundarista é um movimento que surge em decorrência da insatisfação de estudantes com as inúmeras medidas adotadas pelo governo Temer. Iniciado no Estado do Paraná e estendido por todo o país, o movimento ocupa várias escolas e, inclusive, institutos federais e universidades. 05 nov. 2016, Edição 112.
} 
As problematizações apresentadas vão ao encontro do acontecimento das ocupações das escolas pelos jovens estudantes, principalmente de Ensino Médio, em vários estados brasileiros ${ }^{2}$, como podemos notar em algumas imagens no decorrer do texto, ao explicitar atos de resistência e luta pela manutenção dos investimentos na educação pública, sendo assim, contrários à Proposta de Emenda à Constituição (PEC) 55 ou 241, e à Medida Provisória (MP) 746/2016³, convertida na Lei 13.415, aprovada em 16 de fevereiro de 2017, destinada à reestruturação do Ensino Médio ${ }^{4}$.

\section{Figura 2: Movimento estudantil de ocupação de escolas.}

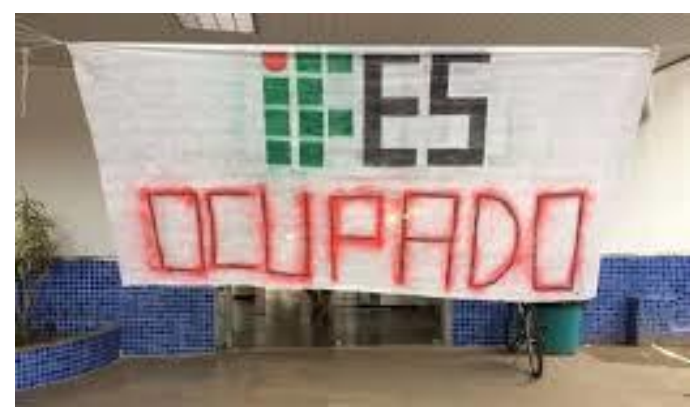

Fonte: <http://www.folhavitoria.com.br/geral/noticia/2016/10/estudantes-ocupam-ifes-em-vitoria-e-provas-do-enem-podemser-afetadas.html>. Acesso em: 22 set. 2017.

Nossa questão se entrelaça àquela disparada pela estudante e a tantas outras. Esse campo problemático não é embrionário, mas se compõe em 'meio' a uma luta histórica que abarca uma linha de imagens e narrativas menores que, rizomaticamente, crescem entre imposições e, também, ramifica outras vozes, outros personagens e possibilidades de pensamentos, como bem ressalta Dayrell (2007, p. 1125),

\footnotetext{
${ }^{2}$ Da parte de estudantes, sobretudo secundaristas, o país assistiu a um amplo movimento de ocupação de prédios públicos. No ápice do movimento, aproximadamente 1.400 instituições educacionais ficaram sob gestão estudantil (FERREIRA; SILVA, 2017, p. 288).

${ }^{3}$ MP 746, de 22 de setembro de 2016. Institui a Política de Fomento à Implementação de Escolas de Ensino Médio em Tempo Integral, altera a Lei 9.394/96, que estabelece as diretrizes e bases da educação nacional, e a Lei 11.494/2007, que regulamenta o Fundo de Manutenção e Desenvolvimento da Educação Básica e de Valorização dos Profissionais da Educação, e dá outras providências.

${ }^{4}$ Segundo Ferreira e Silva (2017, p. 288), A MP 746/2016 foi encaminhada pelo Ministério da Educação ao Congresso Nacional no dia 22 de setembro de 2016. Após quatro meses de tramitação, foi aprovada na Comissão Mista incumbida de apreciá-la; foi então convertida no Projeto de Lei 34/2016, aprovado na Câmara dos Deputados e no Senado Federal, sendo, finalmente, sancionada como Lei 13.415/2017 e passando a compor, desse modo, a Lei de Diretrizes e Bases da Educação (Lei 9.394/1996). Essa nova legislação traz, de modo sucinto, conforme apontam Ferreira e Silva (2017) alterações de grande impacto para o Ensino Médio, como por exemplo, a retirada da obrigatoriedade das disciplinas de Educação Física, Artes, Filosofia e Sociologia; a possibilidade habilitação para docência a quem não possui a formação específica, por meio do reconhecimento de "notório saber. No financiamento, para a garantia da oferta de formação técnica e profissional, passa a ser permitido o uso de recursos do Fundo de Manutenção da Educação Básica (FUNDEB) para realização de parcerias entre as redes públicas e o setor privado, anunciando uma ampla ação de privatização da escola pública de Ensino Médio. À oferta de estudos na modalidade à distância, que poderão ser cursados pelos estudantes e integralizados em seus currículos.
} 
A escola tem de se perguntar se ainda é válida uma proposta educativa de massas, homogeneizante, com tempos e espaços rígidos, numa lógica disciplinadora, em que a formação moral predomina sobre a formação ética, em um contexto dinâmico, marcado pela flexibilidade e fluidez, de individualização crescente e de identidades plurais.

Essas problematizações traçam uma rede de novas articulações e de desejos que ampliam e diminuem suas intensidades, deixando marcas no cenário educativo e político brasileiro, apontando que um outro mundo é possível se efetuar. Nesse sentido, consideramos como Lazzarato (2006), que são as problematizações que produzem o acontecimento.

Assim, as enunciações dos jovens estudantes em movimento de resistência, vão compondo o acontecimento da 'Primavera Secundarista', que coloca em questão as relações postas, impostas e sobrepostas por uma 'sociedade do espetáculo' (AGAMBEN, 2015), que conduzida pelos aparatos midiáticos, vão induzindo a população à aceitação das mudanças impostas, como nota-se na imagem a seguir, alicerçando-se na atuação da 'polícia soberana' (AGAMBEN, 2015), a serviço de um governo soberano que pauta sua política educacional em um enfoque eficienticista e subserviente ao mercado econômico.

\section{Figura 3: Manchete sobre reforma do Ensino Médio e Educação profissional.}

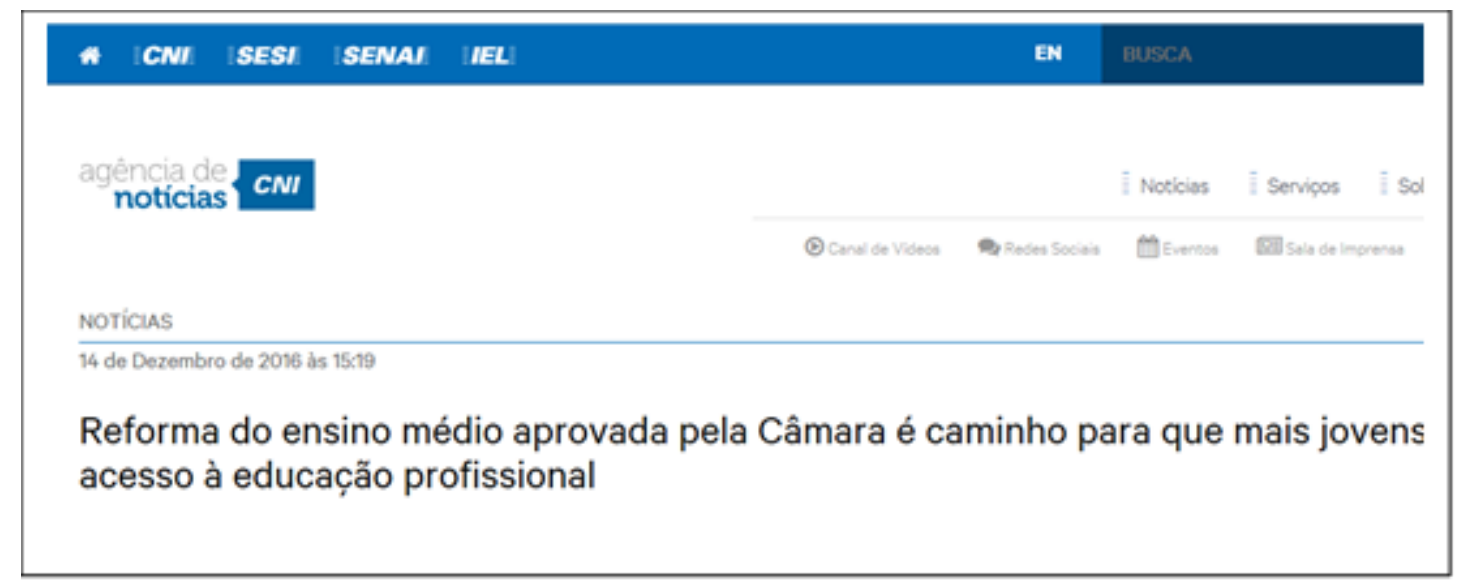

Fonte: <http://www.portaldaindustria.com.br/agenciacni/noticias/2016/12/reforma-do-ensinomedio-aprovada-pela-camarae-caminho-para-que-mais-jovens-tenham-acesso-a-educacao-profissional/>. Acesso em: 22 set. 2017.

$\mathrm{O}$ acontecimento provocado pelas problematizações dos jovens estudantes ao ocuparem as escolas, ao tomarem por várias vezes as ruas de seus Estados, ao enunciarem o tipo de educação que não desejam, deixa pistas para as perguntas “De quem é a escola?" e "De quem é o currículo?", pois elucidam o que há de intolerável nessas propostas educativas contemporâneas. Os estudantes, com sua 'Primavera Secundarista', evocam outras possibilidades de vida, tecem "um processo de experimentação e de criação" que tensiona 
[...] experimentar aquilo que a transformação da subjetividade implica e criar agenciamentos, dispositivos, instituições capazes de se utilizar dessas novas possibilidades de vida, acolhendo os valores que uma geração soube criar: novas relações com a economia e com a política-mundo, uma maneira diferente de viver o tempo, o corpo, o trabalho, a comunicação, outras formas de estar junto e de entrar em conflito etc. (LAZZARATO, 2006, p. 12)

Diante dos fluxos de problematizações postos por múltiplos personagens que produzem discursos, gestos, pensamentos, atos, contrapontos, resistências e lutas nas engrenagens da maquinaria capital, a intencionalidade dessa escrita é cartografar alguns movimentos soberanos que se destinam a dogmatizar a produção do currículo, mais especificamente presentes na MP 746/2016, convertida na Lei 13.415, aprovada em 16 de fevereiro de 2017, destinada a reestruturação do Ensino Médio, assim como, seguir as linhas 'parresiastas'(dizer a verdade) (LAZZARATO, 2014) de (re)existência dos estudantes brasileiros, que impulsionam a questionar de quem é o currículo.

A aposta implicada está em indagar sobre as reverberações dos conceitos "Polícia soberana" e "sociedade do espetáculo" (AGAMBEN, 2015), na imposição de um modelo de educação movido por um processo de 'sujeição social e de servidão maquínica' (LAZZARATO, 2014), que projeta a elaboração de uma vida mercadoria, na qual as pessoas vão assumindo modos de existência convenientes com modelos de subjetivação cunhados por empresas, indústria cultural e instituições do Estado, num trabalho de si para si, ao desenharem novas formas de sujeição capitalista e da valorização econômica, vivenciam o empobrecimento da subjetividade.

Do mesmo modo, ao se questionar sobre "de quem é o currículo", movemos o pensamento também para outras formas de expressão, para o ato da 'parresía' (LAZZARATO, 2014), que mobiliza uma coragem de verdade e de luta, ao deslocar linhas de produção de subjetividade acentradas e disruptivas. A parresía é oriunda de um modo de subjetivação político, capaz de articular sujeito, saber e poder ao implicar "que os sujeitos políticos se constituam como sujeitos éticos, capazes de assumir riscos, lançar desafios, dividir iguais de acordo com suas posições, ou seja, serem capazes de governar a si mesmos e aos outros dentro de uma situação de conflito" (LAZZARATO, 2014, p. 197).

Pensar “de quem é o currículo" perpassa por uma articulação entre relações discursivas e existenciais, por discursos soberanos e/ou não, existências servis, maquínicos ou pela reconfiguração do sensível. Essa articulação ganha o sentido de imagens do pensamento (dogmáticas e políticas), já que entendemos, assim como Bergson (2006), que o universo material é 
constituído por múltiplas imagens num deslizamento constante e heterogêneo, uma se sobrepondo a outra sem provocar a exclusão de nenhuma.

Na sociedade contemporânea, diferentes imagens de pensamentos se fazem coexistentes e contraditórias, o que não nos induz a cair no encanto de (re)apresentar uma única imagem verdadeira, imagem-lei ou imagem-moral sobre o currículo, mas convoca-nos a apostar nas potencialidades de uma 'imagem-cristal' (DELEUZE, 2007), que faz vibrar várias possibilidades de cartografia sobre "De quem é o currículo", a partir das faces de uma imagem soberana, de uma sociedade do espetáculo e da imagem parresiasta dos jovens estudantes em suas apostas de sentir e viver suas experiências educativas em um tempo que dura e perdura.

Diante das múltiplas imagens, as de potência de vida nos/com os currículos escolares são as que nos movem. Desse modo, agenciamos os pensamentos de Agamben (2015), Deleuze (2007), Lazzarato (2006, 2014), juntamente com as imagens divulgadas pela imprensa nacional, as imagens de arquivo pessoal produzidas durante os movimentos e as enunciações dos estudantes do Instituto Federal do Espírito Santo (IFES) ${ }^{5}$, campus Vitória, em 2016, para seguir as linhas de problematizações acontecimentos gerados pela resistência estudantil à reforma do Ensino Médio.

$\mathrm{Na}$ cartografia dessas linhas, seguimos, primeiramente, a apresentação da imagem de um “Currículo soberano e a sociedade do espetáculo", apontando as implicações da Medida Provisória 746/2016, convertida na lei 13.415, aprovada em 16 de fevereiro de 2017 para o currículo do Ensino Médio, ao alterar a LDBN (9.394/96) sem a promoção de um amplo debate com os personagens da cena educativa e, ao efetuar uma política educacional que se pretende mercadológica e soberana, assegurada pela intervenção de uma polícia soberana e pela manipulação midiática no campo do desejo por um currículo tecnicista, que prepare para a atuação profissional, arrastando o corpo para o consumo da vida por relações de "codificação das servidões e das sujeições de todo tipo (materiais, econômicas, semióticas etc.)" (LAZZARATO, 2014, p. 208).

Assim, fomos remetidos às linhas de uma "Primavera Parresiasta como desejo de uma educação não soberana", que destaca a coragem de verdade como um movimento do desejo de coletivizar sentidos e expressões de um currículo com potência de atualização e efetuação de mundos, já que as problematizações e os acontecimentos quando disparam "movimentos políticos não devem apenas resistir e se defender, mas afirmar-se como forças criadoras" (LAZZARATO, 2006, p. 20).

\footnotetext{
${ }^{5}$ Os alunos do Instituto Federal do Espírito Santo foram lembrados e convidados a compor esse texto por terem se engajado de forma intensa no movimento de resistência contra a reforma do Ensino Médio em 2016, atuando efetivamente na ocupação do Instituto, nas manifestações de rua, virtuais, dentre outras.
} 
Emaranhados nessa cartografia, por fim, importou-nos problematizar "De quem é a escola? De quem é o currículo?", ao compreender que escola e currículo são dos personagens que no plano de imanência, buscam em suas lutas e desejos a "formação do ethos, do bios, da existência “militante" [...] (p. 209), indagando sobre "as formas de acesso à verdade que serão capazes de formar esse ethos, e também [sobre] as estruturas políticas no interior das quais esse ethos será capaz de afirmar a sua singularidade e diferença" (LAZZARATO, 2014, p. 213).

\section{O CURRÍCULO SOBERANO E A SOCIEDADE DO ESPETÁCULO}

A composição curricular, suas prescrições e definições teórico-metodológicas apontam para um campo de disputas, lutas e relações de saber e poder, trazendo em seu bojo relações 'discursivas e existenciais' imersas em redes de 'sujeição social e de servidão maquínica' (LAZZARATO, 2014).

Determinar o quê, como e quando uma pessoa deve aprender, além de seus percursos na vida escolar, é algo muito almejado pela lógica de produção de subjetividade capitalista, que opera, segundo Lazzarato (2014, p. 17), por dispositivos de sujeição social "atribuindo a nós uma identidade, um sexo, um corpo, uma profissão, uma nacionalidade" Dito de outro modo, as escolas visam atribuir ao currículo, fechado em sua consciência iluminada pelo mercado econômico, representações no indivíduo vocacionado ao trabalho servil e pelo comportamento de bom pensador que busca reafirmar o que lhe é ensinado.

Ao mesmo tempo em que a sujeição social visa à transformação do uno, de um currículo uno, o capitalismo lança mão de máquinas técnicas e sociais que atravessam a composição curricular e operam processos de subjetivação de uma servidão maquínica, agindo para além do sujeito individuado, assistindo "nossos modos de falar, ouvir, escrever, e sentir" (LAZZARATO, 2014, p. 17).

A subjetividade e os processos de subjetivação que emergem pelos ideais do capital produzem um currículo máquina, que trai a estabilidade e a individualidade dos papéis desejáveis e preestabelecidos, ao instaurar um agenciamento que não faz mais "distinção entre humano e não humano, sujeito e objeto, palavras e coisas" (LAZZARATO, 2014, p. 18).

O currículo produzido em redes de sujeição social e de servidão maquínica é aquele que sujeita as pessoas às padronizações dos interesses mercadológicos e que as lançam em redes corporativas e midiáticas, que encobrem a educação com conceitos como "direito, nação, povo, democracia e vontade geral" não deixando transparecer "uma realidade que não tem mais nada a ver 
com aquilo que tais conceitos designavam" (AGAMBEN, 2015, p. 101). Emerge, assim, a imagem de um currículo soberano com vontade de verdade.

O currículo soberano remete-nos ao conceito de soberania trabalhado por Agamben (2015), ao problematizar que tal conceito é produzido por relações diretas e paradoxais entre violência e direito, vivente e linguagem, sentida e vivida por meio de expropriação e medo. A lei atuaria na manutenção da linguagem (hegemônica, linear) que retiraria dos homens sua condição de seres de enunciação, entregando-os à violência, que num estado de exceção se torna regra.

A soberania de um currículo tem a ver com a sacralização de leis educacionais verticalizadas, que expropriam a condição linguística e existencial de estudantes, professores, profissionais da educação e sociedade em geral, ao entregá-los aos ideais de um estado de exceção e de sujeitos soberanos que, macropoliticamente, impõem uma vida nua, individualista e afônica, ligada à servidão, aos imobilismos e às engrenagens do capital. Agamben (2015, p. 104) contribui então, ao ressaltar que "o estado de exceção é a regra, que a vida nua é imediatamente portadora do nexo soberano e, como tal, ela é hoje abandonada a uma violência tanto mais eficaz quanto anônima e cotidiana".

A ideia de um currículo soberano é tratada aqui como um modo de mover o pensamento para o debate sobre a alteração da Lei de Diretrizes e Bases da Educação Nacional (9.394/96), pela aprovação da Medida Provisória 746/2016, convertida na lei 13.415, aprovada em 16 de fevereiro de $2017^{6}$, que visa à reestruturação do currículo do Ensino Médio.

Figura 4. Aprovação da Medida Provisória 746 pelo Senado.

\title{
Senado aprova MP que reforma o ensino médio; texto vai à sanção presidencial
}

\author{
Escolas poderão escolher o que vão ensinar em $40 \%$ da carga horária; português, matemática, inglês, \\ artes, educação fisica, filosofia e sociologia são obrigatórios.
}

Fonte. 〈https://g1.globo.com/politica/noticia/senado-aprova-texto-base-da-mp-da-reforma-do-ensino-medio. ghtml >. Acesso em: 22 set. 2017.

Tomamos as manchetes e as imagens divulgadas na mídia durante os meses de novembro e dezembro de 2016 e janeiro de 2017, o período de aprovação da Medida Provisória/Lei e, as

\footnotetext{
${ }^{6}$ A medida foi aprovada em 08/02/2017. Disponível em: 〈http://br.reuters.com/article/domesticNews/idBRKBN15N2V7〉.
} 
enunciações dos estudantes do IFES/VITÓRIA, para problematizar a instauração de um currículo soberano intermediado pelo 'estado de exceção' (AGAMBEN, 2015) que na legitimação da violência pela ação da polícia e por uma 'sociedade espetacular' (id.) expropria a linguagem comum dos seres humanos, assim como a 'função existencial' (LAZZARATO, 2010).

Em meio a uma onda de protestos espalhados pelo país e ocupações de escolas, diante de muitas críticas de pesquisadores do campo educacional e do currículo, o texto foi aprovado sem que fosse tecido amplo debate com a sociedade e com os sujeitos que praticam os diferentes cotidianos escolares produzidos no Brasil.

Empenhados em denunciar e questionar a imposição de um modelo de política educacional vinculado à governança da soberania, estudantes, principalmente, os secundaristas, lançaram mão de movimentos de resistência, como debates, fóruns, ocupações de escolas, ocupações e manifestações de ruas para que pudessem compreender os movimentos instaurados com a Medida Provisória e, também, como uma maneira de problematizar, de resistir e provocar a sociedade a posicionar-se contrariamente a tal reforma.

Figura 5. Compilado de imagens do Ocupa Ifes - Vitória.
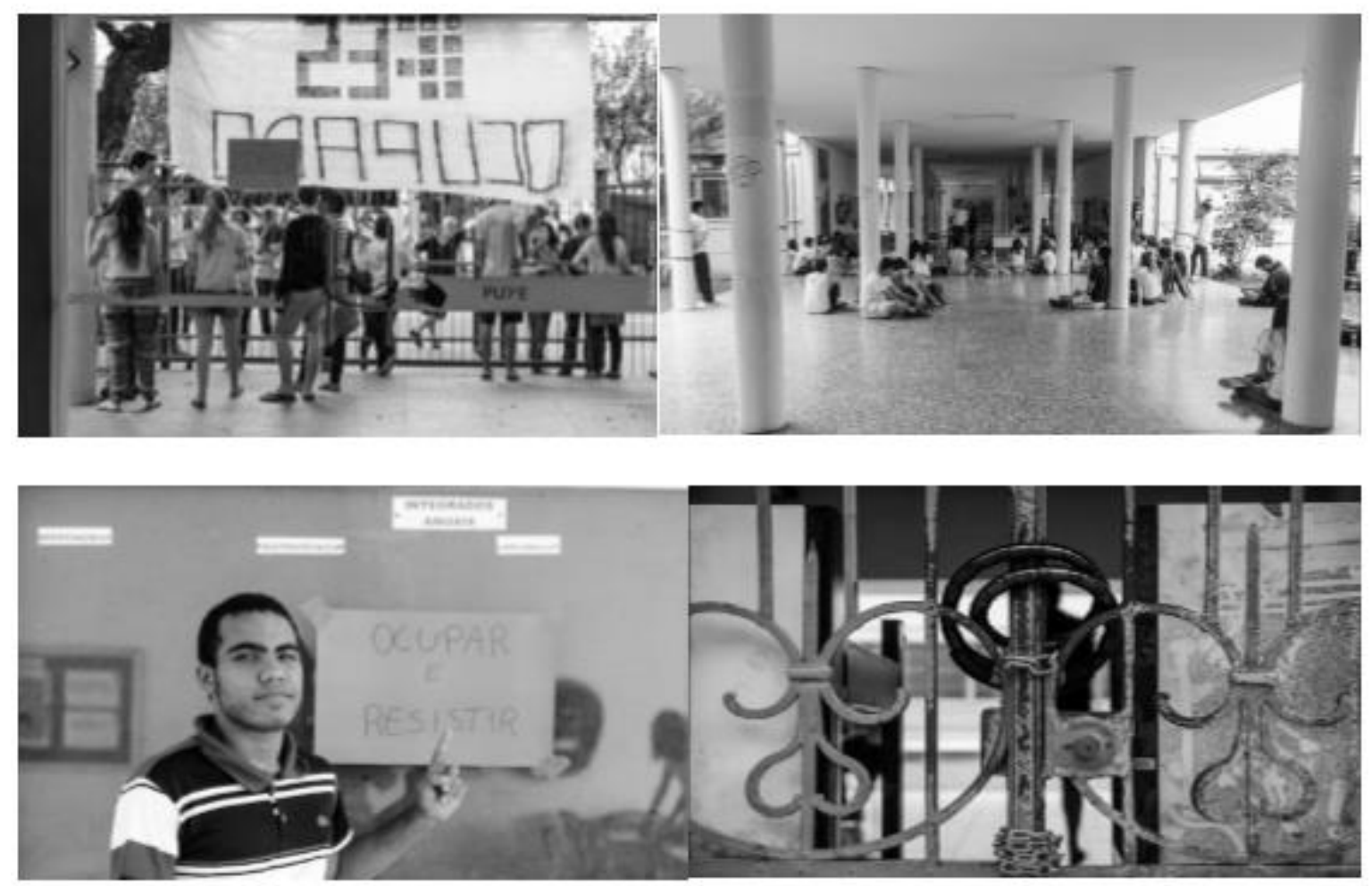

Fonte. 〈https://www.facebook.com/spimenteljs/media_set?set=a.10154644691358416.1073741849.692248 415\&t ype=3〉. Acesso em :22 set. 2017.

Porém, os jovens encontraram dois entraves conhecidos na história do Brasil: a atuação da soberania em seu agenciamento de polícia e a manipulação da grande mídia. Esses entraves traziam 
em seu bojo a configuração da sujeição social pela repressão ao movimento dos corpos e dos pensamentos pela violência física e simbólica na figura da polícia. A busca incessante por calar e conter os estudantes que, por dias e dias, ocupavam escolas e se reuniam formando redes micropolíticas de resistência que se espalhavam pelo país, manifestava o "ingresso definitivo da soberania na figura da polícia" (AGAMBEN, 2015, p. 97).

\section{Figura 6. Embate velado entre estudantes e a polícia.}

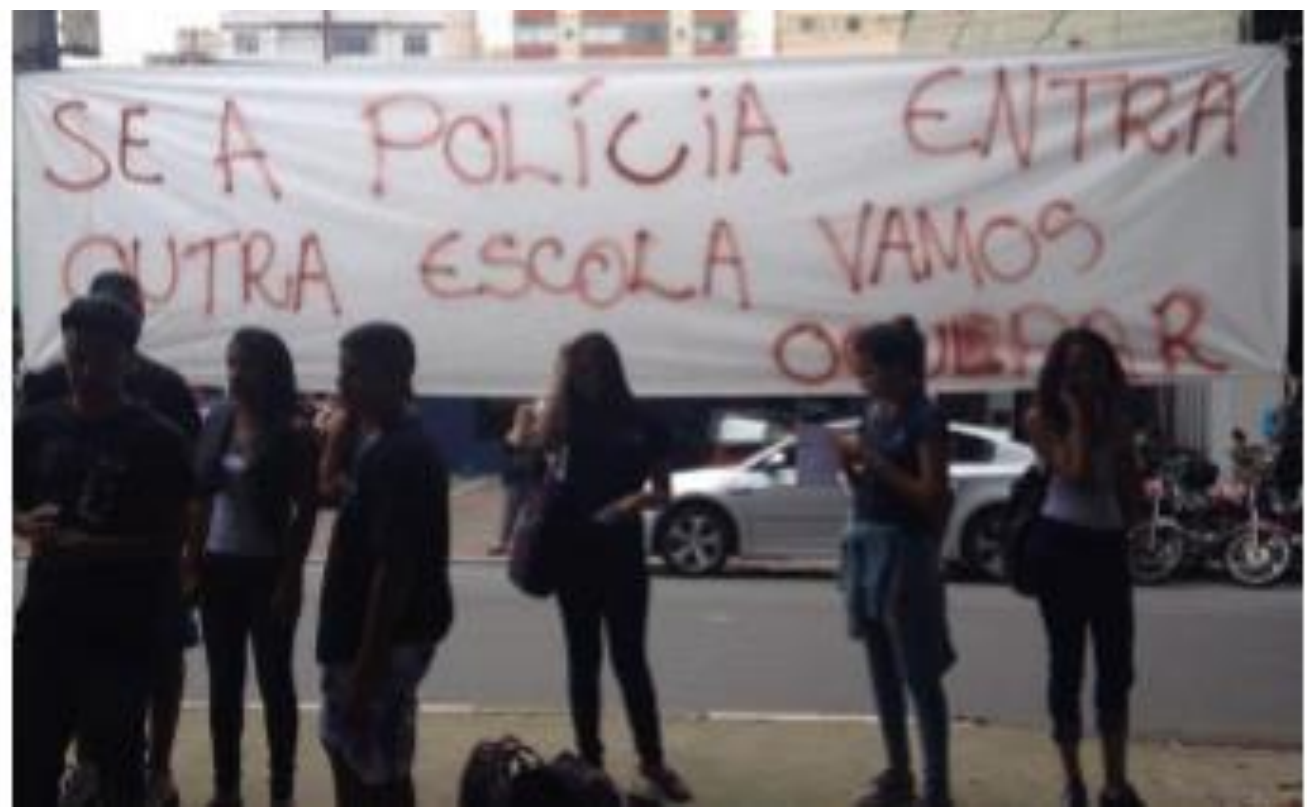

Fonte: <https://www.google.com.br>. Acesso em: 22 set. 2017.

A figura da polícia fez-se, permanentemente, presente durante os atos da "Primavera Secundarista", com a justificativa de ser tranquilizadora, pacificadora e de estar a serviço da manutenção da segurança e da ordem pública, colocando-se como uma "ameaça a quem transgride o direito (a exibição ocorre de, fato, nos lugares públicos mais pacíficos e, em particular, durante cerimônias oficiais), quanto a exposição daquela violência da qual era testemunha a proximidade física entre cônsul e lictor"(AGAMBEN, 2015, p. 98).

A imagem abaixo atualiza as experiências de jovens estudantes que ocupavam a Secretaria de Educação do Estado do Espírito Santo (SEDU), durante o movimento de resistência contra a aprovação da PEC 55 e da Medida Provisória MP 746, no dia do cumprimento da ação de retomada de posse do prédio. $\mathrm{O}$ ato da polícia expunha sua força com seus carros, armas e sujeitos soberanos, prontos para expulsar os estudantes em ocupação e professores que estavam do lado de fora do prédio em apoio ao movimento. 
Figura 7. Desocupação da SEDU / Espírito Santo em novembro de 2016.
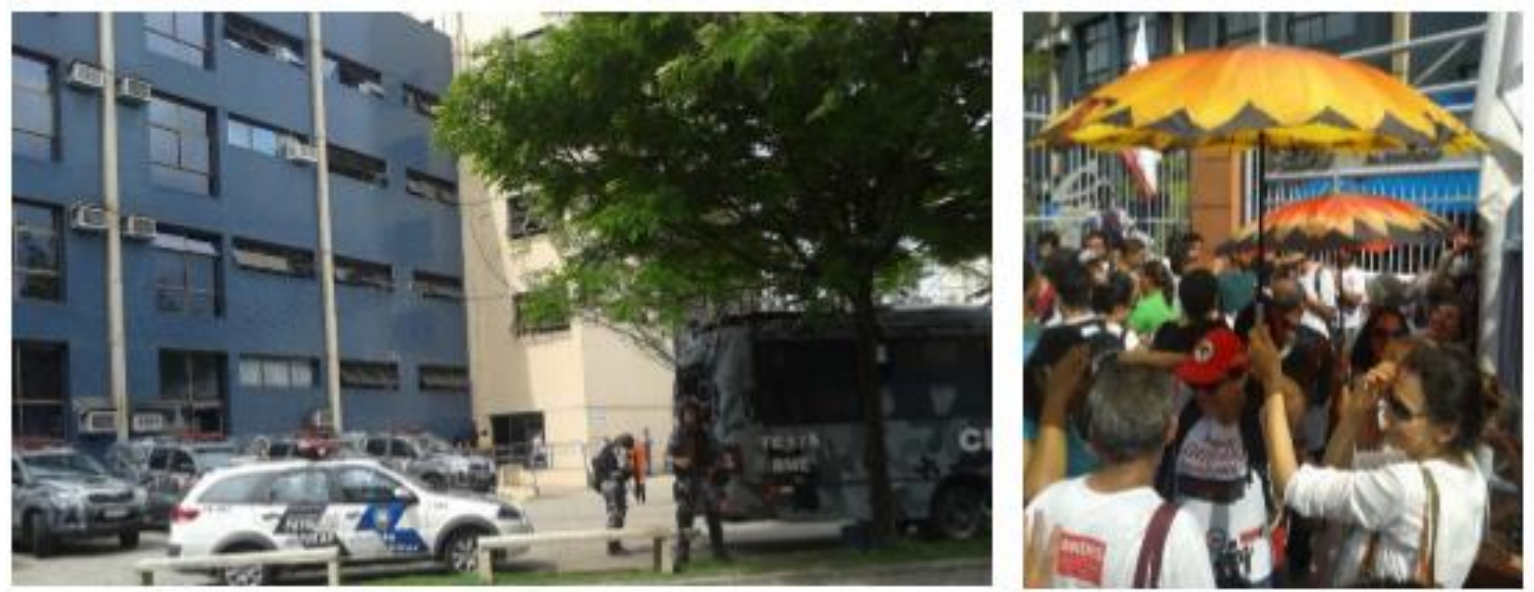

Fonte: Arquivo pessoal dos autores.

Outra barreira estabelecida diante do movimento dos estudantes foi a servidão maquínica promovida por meios de comunicação que reafirmavam o poder de soberania do Estado que

[...] deixa sobreviver em todos os lugares seu invólucro vazio, como pura estrutura de soberania e de domínio, a sociedade em seu conjunto é, por sua vez, entregue irrevogavelmente à forma da sociedade de consumo e de produção orientada ao único fim do bem-estar (AGAMBEN, 2015, p. 103-104).

A soberania que se enredava entre as formas de atuação da polícia e os agenciamentos midiáticos que produzem a "sociedade do espetáculo", buscava esgarçar os fluxos de resistência dos jovens estudantes, considerando-os como vândalos, culpados pelo atraso no calendário escolar, como sujeitos de não trabalho, resgatando o discurso "inimigos do país", agora com a roupagem "inimigos da democracia", pois a "investidura do soberano como policial tem outro corolário: torna necessária a criminalização do adversário" (AGAMBEN, 2015, p. 99-100).

Essa imagem criada e sustentada sobre a 'Primavera Secundarista' só se tornou possível de ser enunciada pela 'grande' mídia devido às ações de soberania, que criam dentro de um estado de direitos, o 'estado de exceção', que segundo Agamben (2015), se estrutura na 'indistinção entre violência e direito'. 
Figura 8. Movimento Brasil Livre atuando na desocupação das escolas.

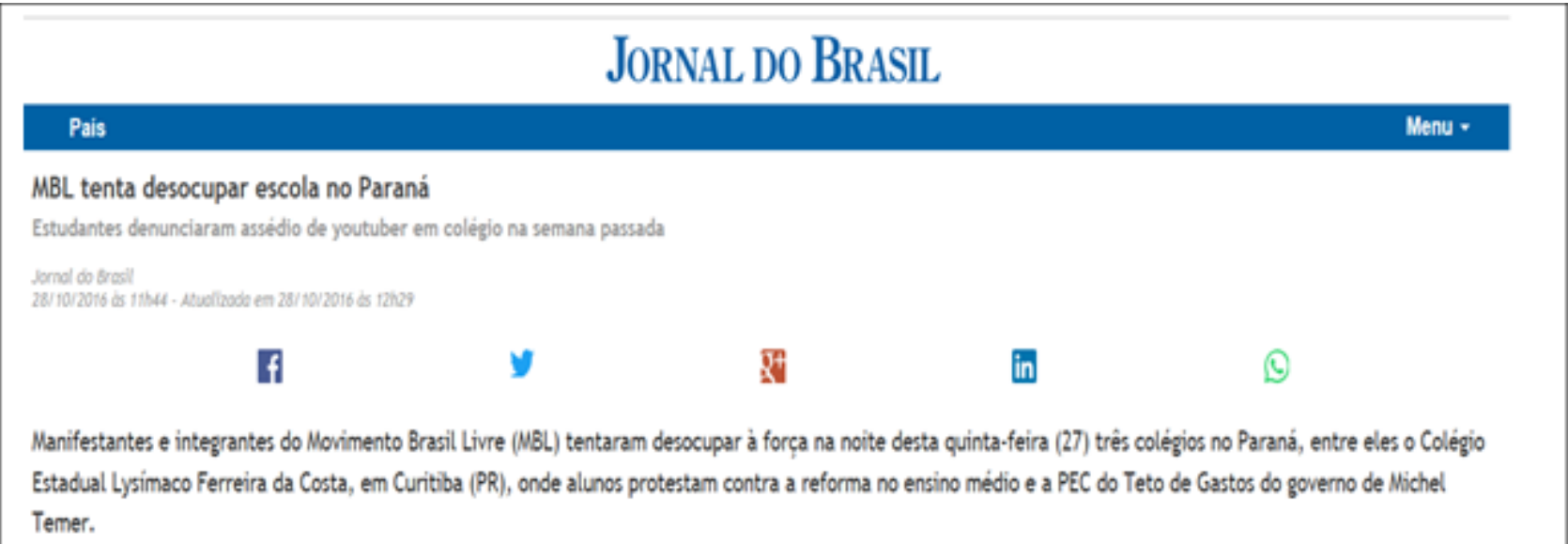

Fonte: <http://m.jb.com.br/pais/noticias/2016/10/28/mbl-tenta-desocupar-escola-no-parana/>. Acesso em: 22 set. 2017.

Essa indistinção pôde ser sentida na pele por estudantes em algumas atuações da polícia no cumprimento das ações de retomada de posse das escolas ocupadas, assim como, por jovens estudantes e profissionais da educação que, em manifestações contrárias à votação da Medida Provisória e à PEC 55, foram surpreendidos com a represália da polícia em Brasília, confirmando o fato de que

[...] é a polícia, contrariando a opinião comum que vê nela uma função meramente administrativa de execução de direito, é talvez o lugar no qual se põe a nu, com maior clareza, a proximidade e, quase, a troca constitutiva entre violência e direito que caracteriza a figura do soberano (AGAMBEN, 2015, p. 98).

\section{Figura 9. Compilado de imagens de repressão policial à manifestação contrária à PEC 55 em} Brasília.
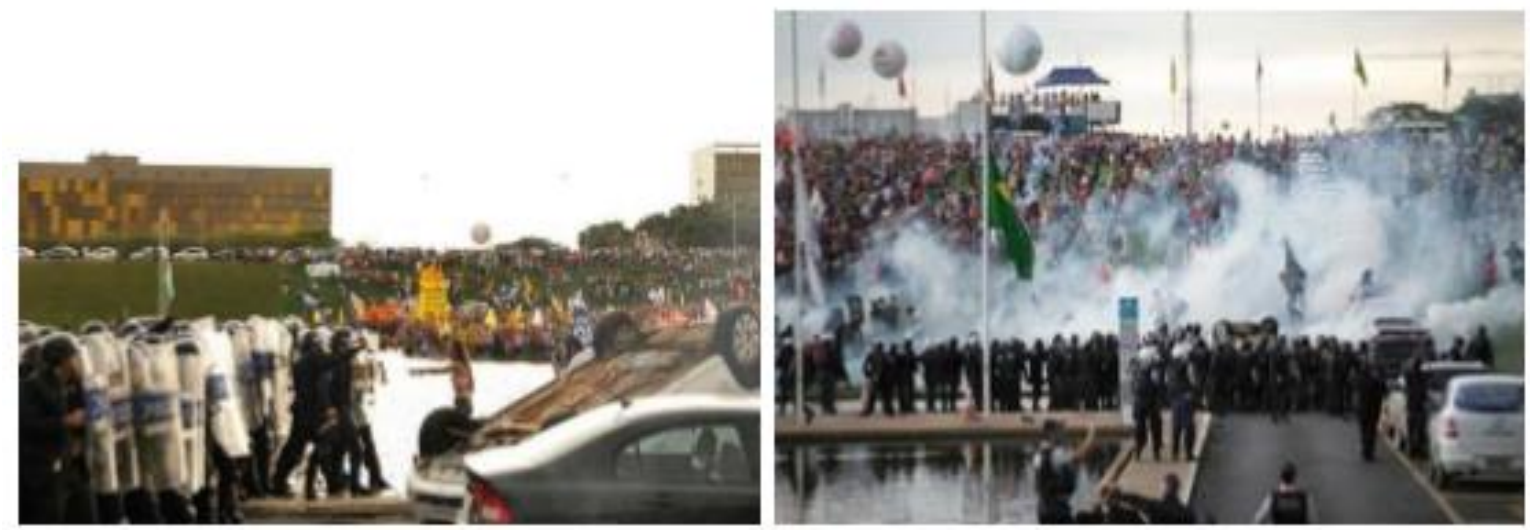

Fonte: <https://acaopopularsocialista.com>; e <http://www.correiobraziliense.com.br>. Acesso em: 22 set. 2017.

Assim, o que se tem configurado é a composição de um currículo soberano, que se impõe sem considerar a complexidade da elaboração de uma política educacional, desconsiderando as 
vozes, experiências, saberes e poderes dos sujeitos que praticam os espaços e tempos escolares, criminalizando os que pensam diferente, os que lutam por outras formas de existências enviesadas pela educação, pela justificativa de garantia da "ordem pública" e de "segurança" na figura da polícia e da "verdade" pela sociedade do espetáculo.

Os estudantes problematizam a imposição, pelo estado de exceção, de um currículo soberano ao dizer que

A reforma do ensino está sendo feita de forma errada. Algo tão importante e que interfere em toda a sociedade dever haver ampla discussão com a população, além de especialistas na área. O governo lançou essa pauta sem nenhuma discussão com a população, retirando no primeiro projeto matérias ligadas ao entendimento da sociedade e política, como sociologia e filosofia, o que indica que intenção de manipulação pela educação (Estudante C. Novembro de 2016)

O currículo soberano apresenta-se pela vontade de verdade, de homogeneização dos saberes, das experiências, pelo controle dos pensamentos e dos corpos. Busca-se uma vontade de verdade e de saber cunhada pelos princípios da sujeição social a uma vida mercadoria e pela servidão maquínica do pensamento dogmático, adormecido pelo medo e pela alienação da linguagem humana.

Acredito que a pauta que levou muitas escolas a ocuparem, como a MP 746 e a PEC 55, está sendo deliberada de forma impositiva. As mudanças estão sendo empurradas com a desculpa de que é para o bem da economia, mas até onde a economia é considerada importante para a educação? Entendo que este tipo de medida é uma forma bruta de excluir o senso crítico e questionador, transformando esses afetados em alienados/massa de manobra (Estudante A, nov. 2016).

A soberania e a investidura em uma sociedade do espetáculo, buscavam um contramovimento diante de tanta resistência contra a reforma do currículo do Ensino Médio. Agenciavam uma imagem-propaganda de ensino ideal, para estudantes vocacionados, que escolhem profissão por amor. 
Figura 10. Propaganda Novo Ensino Médio- Governo Federal- 2017.
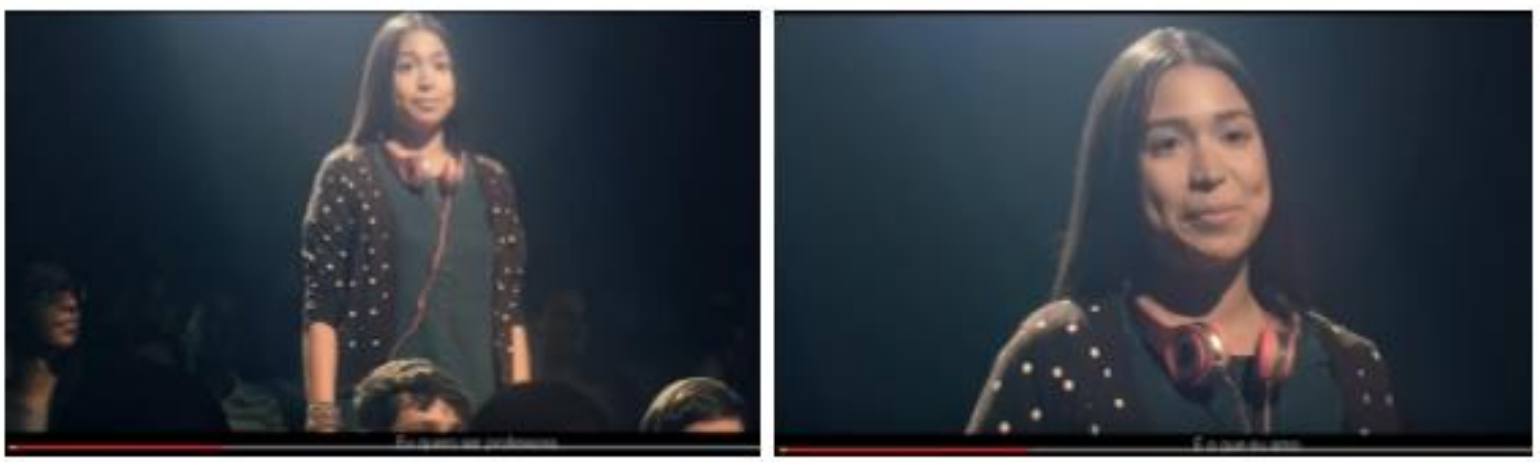

Fonte: 〈https://www.youtube.com/watch?v=WVLy3oCIZuc〉. Acesso em: 22 set. 2017.

As imagens instituídas pelo governo movimentam o pensamento dos estudantes na tentativa de fissurar e até quebrar os clichês que encobrem as maquinarias que produzem uma vida de sujeição e servidão. Ao colocarem em análise os movimentos reformistas midiatizados de investimento na sociedade do espetáculo, os jovens, assim como Agamben (2015, p. 83) alertam que "não é dito, no entanto, que a tentativa do espetáculo de manter o controle do processo, que ele mesmo contribuiu para pôr em movimento, seja destinada a ter êxito".

O governo atual, através de propostas recentes, tem deixado claro que não governa para o povo. A MP 746 está sendo imposta pela sabotagem ao pensamento crítico. Vem com a "Escola sem partido", e pela tentativa de extinguir as matérias críticas disfarçadas de escolhas do aluno. Atualmente, a propaganda do Governo Federal vem dizendo que a reforma é baseada em sistemas educacionais de países desenvolvidos, o que não é necessariamente mentira ou ruim, mas se eles considerassem as ideias de Paulo Freire, saberiam que a realidade dos estudantes atendidos e as suas carências são completamente diferentes (Estudante D, nov. 2016).

As imagens-propaganda apresentam ainda estudantes felizes e dispostos a ingressarem rápido no mercado de trabalho, veiculando a reforma imposta a melhorias na qualidade de educação e de atuação dos estudantes brasileiros.

\footnotetext{
${ }^{7}$ A discussão da escola sem partido apresentada na narrativa do estudante, como destaca Penna (2015), trata de [...] um movimento criado por um advogado chamado Miguel Nagib, para combater o que ele percebia como doutrinação ideológica nas escolas.Em 2007, quando o Ali Kamel começa uma grande polêmica em torno de sua crítica do livro didático Nova História Crítica, do Mario Schmidt, o Escola Sem Partido ganha visibilidade junto com o tema da doutrinação de esquerda.No entanto, é justamente no momento que o Escola Sem Partido se aproveita do combate à ideologia de gênero, tornando-o uma das suas bandeiras, que ele dá um salto qualitativo.
} 


\section{Figura 11. Propaganda Novo Ensino Médio- Governo Federal- 2017.}
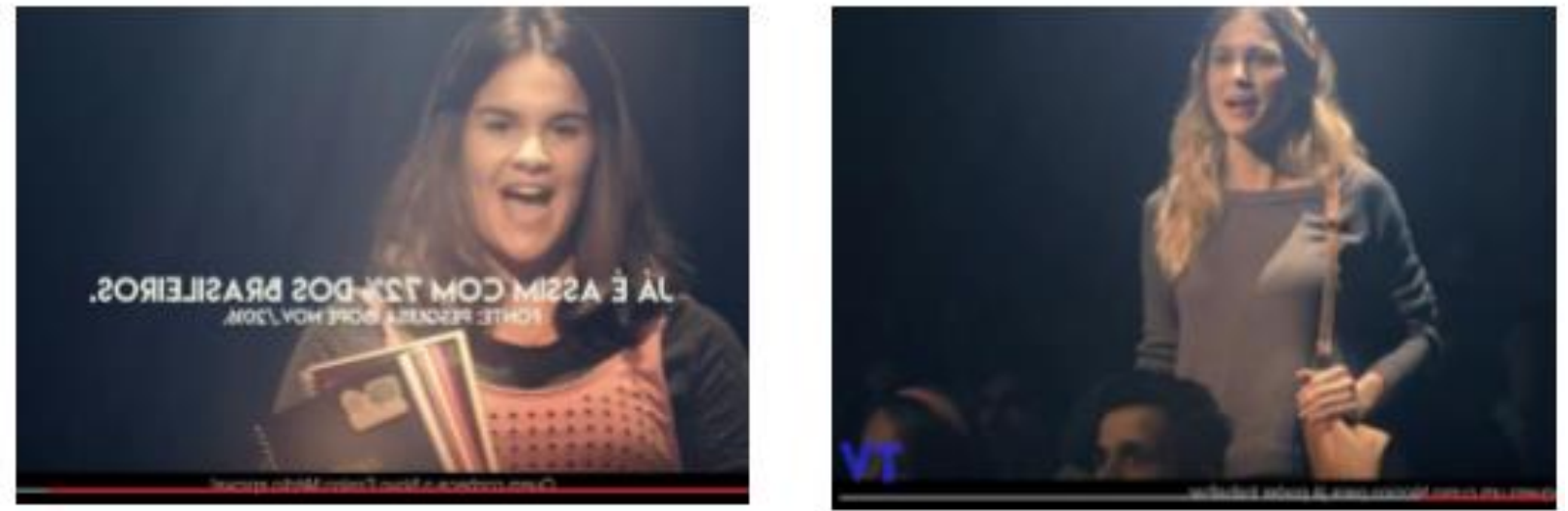

Fonte: <https://www.youtube.com/watch?v=WVLy3oCIZuc>. Acesso em: 22 set. 2017.

Assim, o currículo soberano se vale de imagens-alienação, que buscam adormecer o pensamento da população e conformá-lo aos discursos espetaculares, que se inscrevem pela midiatização da reforma curricular, pelo lançamento de múltiplas manchetes que frisam a necessidade de um currículo reformado aos moldes de países europeus, afirmando uma juventude para o trabalho e, que, tratam a recusa dos estudantes a totalizações, como vandalismo, fixando uma língua única, uma verdade e um currículo espetacular. A serviço da força motriz do capital, Agamben (2015, p.79) argumenta que é

[...] claro que o espetáculo é a linguagem, a própria comunicabilidade e o ser linguístico do homem. Isso significa que a análise marxiana é integrada no sentido de que o capitalismo [...] não estava voltado somente para a expropriação da atividade produtiva, mas também e, sobretudo, à alienação da própria linguagem, da própria natureza linguística e comunicativa do homem, daqueles logos no qual um fragmento de Heráclito identifica o comum. A forma extrema dessa expropriação do Comum é o espetáculo, isto é, a política na qual vivemos.

A soberania e a sociedade do espetáculo se engendram na busca pela expropriação da linguagem comum, na busca pela alienação e servidão, como a manchete a seguir destaca, ao denunciar o financiamento do Governo Federal a jovens com grande repercussão nas redes sociais para falarem bem do Novo Ensino Médio. 
Figura 12. Manchete do jornal Folha de São Paulo.
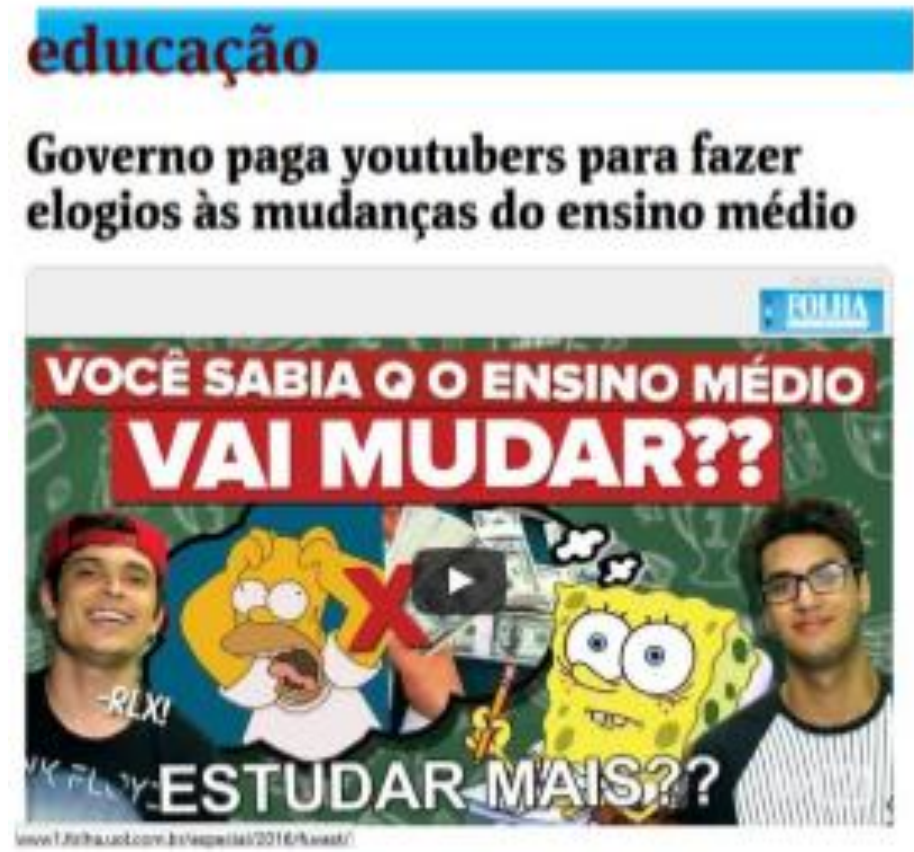

Fonte: 〈http://www1.folha.uol.com.br/educacao/2017/02/1859532-governo-paga-youtubers-parafazer-elogios-as-mudancasdo-ensino-medio.shtml >. Acesso em: 22 set. 2017.

Esse currículo soberano e sua vontade de verdade são da ordem do espetáculo, visam à expropriação do sentido do comum pela manipulação midiática no campo do desejo por um currículo tecnicista, que prepare para a atuação profissional, arrastando o corpo para o consumo da vida por relações de "codificação das servidões e das sujeições de todo tipo (materiais, econômicas, semióticas etc.)"(LAZZARATO, 2014, p. 208).

A metanarrativa criada e sustentada pela força da grande mídia afirma uma língua desconhecida pelos praticantes das escolas, atuando no campo do desejo de um currículo que seja capaz de "salvar" o Brasil dos baixos índices nos exames internacionais que aferem a qualidade da educação mundial, por intermédio de empresas e fundações privadas.

Figura 13. Manchete do jornal $O$ Globo.

O GLOBO $\equiv \ldots$ SOCIEDADE
Pesquisa revela insatisfação com
excesso de teoria e falta de prática do
atual modelo de ensino
Estudo da Fundaç̧o Lemann mostra como jovens e professores enxergam a educaçio no
Brasil

Fonte: 〈http://oglobo.globo.com/sociedade/educacao/pesquisa-revela-insatisfacao-com-excessode-teoria-falta-de-praticado-atual-modelo-de-ensino-16445918>. Acesso em: 22 set. 2017. 
Os estudantes, atentos às justificativas da reforma, denunciam que os indicativos expostos nos exames nacionais são utilizados como argumentos que favorecem a ordem do instituído pelo governo, e outras análises, também a partir dos exames, são desconsideradas. "As mudanças propostas pela MP 746 são justificadas pelo alto índice de evasão escolar. No último exame do PISA, o Brasil apareceu entre os dez piores dos setenta países avaliados, portanto, o problema de evasão escolar não é o único (Estudante E., nov. 2016)".

Portanto, a comunicabilidade exercida pela soberania de um currículo é aquela capaz de desconsiderar "as singularidades individuais e coletivas, que [...] desenvolvem uma dinâmica de subjetivação que é, ao mesmo tempo afirmação da diferença e composição de um comum não totalizável” (LAZZARATO, 2006, p. 205).

Entretanto, a 'função linguística e existencial' (LAZZARATO, 2010) não se encontra dissociada e nem totalmente cristalizada. A imposição de um currículo soberano não significa a assunção dessa forma de vida por todos. Outras linhas de autoposicionamento e afecções vão se afirmando para além de relações discursivas presentes no texto aprovado, atualmente exposto à sociedade em forma de Lei, assim como, não são tomados pelo medo e pela repressão do ato de uma polícia soberana.

Diante do currículo soberano, também se apresentam relações existenciais diferenciais, movediças, resistentes e inquietas, que se recusam o simples aceitar, que praticando outros modos de existir dizem, cotidianamente, aos soberanos " que tal criminalização pode voltar-se, a qualquer momento, contra eles" (AGAMBEN, 2015, p. 100).

Contrários a um currículo soberano e retomando a questão "De quem é o currículo", cabe lembrar que a ruptura com as significações dominantes e soberanas que atravessam as formas de vida passam também por aspectos não discursivos, da ordem do não-sentido, pelo a-significante, que pelo viés político se materializa na forma de resistências, lutas, manifestações, revolta, suspendendo o tempo burocrático e repressor, criando "outros possíveis dos quais poderão proliferar, se houver consistência, outras subjetivações e outras cristalizações existenciais" (LAZZARATO, 2014, p. 189)

\section{PRIMAVERA PARRESIASTA COMO DESEJO DE UMA EDUCAÇÃO NÃO SOBERANA}

Contrários à vontade de verdade do currículo soberano, os estudantes brasileiros foram tecendo uma 'Primavera Secundarista' em meio a pensamentos e ações dotados de uma coragem de verdade. Coragem que exige um autoposicionamento com anseio de coletivizar outras apostas 
estéticas, 'por que há evidências de enunciações' (LAZZARATO, 2014) e, outro modo de vida ético-político, 'que transversaliza com outros níveis heterogêneos (políticos, sociais, econômicos, artísticos etc.)' (LAZZARATO, 2014, p. 187), recusando os impostos pela sociedade espetacular da violência, consumo e soberania.

As problematizações criadas pelos estudantes diante da reforma do Ensino Médio em seus movimentos de ocupações, manifestações e resistências foram compondo o acontecimento da 'Primavera Parresiasta', que está relacionado com o ato de dizer a verdade (parresía), mas a verdade não no sentido de igualdade, de homogeneização e hegemonia. Dizer a verdade ganha, no sentido Foucaultiano, a força de 'diferenciação ética' (LAZZARATO, 2014), que destaca o desejo de experimentação do currículo escolar como potência de atualização e efetuação de mundos.

Assim, os acontecimentos da "Primavera Parresiasta" produziram não somente fechamento de escolas, atrasos no calendário escolar, embates com a polícia ou desgaste com a sociedade manipulada pela grande mídia, mas foram capazes de apontar que, "movimentos políticos não devem apenas resistir e se defender, mas afirmar-se como forças criadoras" (LAZZARATO, 2006, p. 20).

A força criadora presente nas enunciações de alguns estudantes do Instituto Federal do Espírito Santo, do campus Vitória, integrantes da Primavera Secundarista, durante os atos de resistência aos processos de reforma do Ensino Médio em 2016, mobiliza a continuar indagando "De quem é o currículo?".

Em seus movimentos políticos, faziam mostragem de que o currículo não pode prestar aos serviços da vontade de verdade e de homogeneização. Remetiam a questão que Lazzarato (2014, p. 195) resgata de Foucault, ao discutir sobre verdade: "Que vida, que poderes, que saberes e quais práticas podem sustentá-las?

Diante dessas questões, os estudantes, em sua busca por dizer a verdade, enunciam que o currículo não pode ser da ordem da soberania.

É errado pensar em uma reforma de currículo educacional se a mesma não é primariamente destinada à população (estudantes).Eu não consigo enxergar como um papel de otimização desse currículo, principalmente pelo caráter de urgência que está sendo submetida, nos leva a questionar os verdadeiros beneficiados (Estudante B, nov. 2016).

Questionar a verdade, dizer a verdade sobre o currículo, indagar e responder sobre "De quem é o currículo" demanda a diferenciação ética, que segundo Lazzarato (2014, p.196) ressalta, 
exige a coragem da verdade, ou seja, o ato da parresía (para que o dizer a verdade possa se exercer) que precisa ser sustentado "tanto pela politeia (a Constituição garantindo a igualdade), quanto pela isegoria (qualquer um podendo falar publicamente e dizer sua palavra sobre assuntos da cidade)".

Porém, não é somente o direito de falar que faz alguém falar. Muitos estudantes, em suas enunciações, apontavam para a necessidade da fala, da voz estudantil como um convite feito a parresía; "os estudantes têm que levantar a voz e mostrar que quem faz a escola são eles e que a opinião e a vontade deles não podem ser ignoradas” (Estudante F, novembro de 2016).

O convite à parresía, a exercer a coragem da verdade foi feito, mas só se atualiza como força criadora, por intermédio da dunasteia (o que efetivamente faz falar) que é "a potência, a força, o exercício e a efetivação real do poder de falar que mobilizam relações singulares do enunciador consigo mesmo e com aqueles a quem ele se dirige. A dunasteia que se exprime na enunciação é uma força de diferenciação ética [...] uma tomada de posição em relação a si, aos outros e ao mundo" (LAZZARATO, 2014, p. 196).

$\mathrm{Na}$ efetivação real do poder de falar, os estudantes potencializam os debates, as manifestações e resistências ao se oporem aos maquinismos que operam, em relação ao currículo, processos de subjetivação servis.

"Os alunos têm que ter a voz. A escola - alunos e professores - devem decidir o que é melhor. Nós não somos máquinas do Estado que faz só o que gerará lucro para ele: nós somos cidadãos livres e queremos nosso direito de aprender tudo que está disponível a nós. (Estudante F, nov. 2016).

"O currículo escolar pertence à sociedade como um todo. Cabe a ela, portanto, a definição do conteúdo do currículo. Para tanto, é importante buscar formas de organização e representação popular que sejam capazes de contemplar também os anseios dos grupos minoritários e marginalizados" (Estudante G, nov. 2016).

A "Primavera Parresiasta" que emerge com o movimento estudantil como desejo de uma educação não soberana, provoca, convida, estabelece enfrentamentos, assume os riscos de dizer e lutar pela verdade. Constitui-se como uma força de agenciamento de outros posicionamentos, afecções e pensamentos diferentes dos massificados e idealizados pela soberania, pelos assegurados pelo ato da polícia soberana, ou pelas engrenagens da sociedade do espetáculo. A "Primavera Parresiasta" contrária a uma educação soberana, "reestrutura e redefine o campo de ação possível, tanto para si como para os outros" (LAZZARATO, 2014, p. 197) permitindo, constantemente, colocar em questão "De quem é a escola? De quem é o currículo?" 


\section{“DE QUEM É A ESCOLA? DE QUEM É O CURRÍCULO?”. NOTAS EM SUSPENSÃO}

As problematizações tecidas pelo movimento estudantil, contrário às reformas educacionais presentes na MP 746 e PEC 55, provocaram o acontecimento da "Primavera Secundarista" desencadeado em vários estados do Brasil, no final de 2016 e início de 2017. As problematizações se cunharam nos corpos e pensamentos de jovens estudantes que ocuparam ruas, escolas e instituições públicas na busca parresiasta por dizer a verdade, ou seja, por uma subjetivação política que não se contenta ou adormece com a tentativa de instalação de um "consenso democrático constitui a neutralização da parresía” (LAZZARATO, 2014, p. 198).

O acontecimento que emerge é por uma educação não soberana, não servil a tirania da dominação do pensamento e da educação brasileira. Os estudantes, em seus atos e falas, foram compondo problematizações que não se entregavam às pressões de uma sociedade do espetáculo ou às opressões de uma polícia soberana. A soberania de um currículo imposto agenciou um contra movimento, a "Primavera Secundarista", que na constituição de sujeitos éticos-políticos, assumiu o risco, lançou desafios e dividiu o país com suas posições, sendo capaz "de governar a si mesmos e aos outros dentro de uma situação de conflito”. (LAZZARATO, 2014, p. 197).

Esse acontecimento fez uma abertura dos possíveis, com a percepção de que

Encontramo-nos muito mais próximos da política do que acreditávamos. Isso por que o conflito político [...] como alternativa subjacente às condições de possibilidade dadas (capital/trabalho, homens/mulheres, trabalho/lazer) e conflito como denegeração de qualquer prévia atribuição de papeis, de funções, de percepções, de afetos [...] da qual podemos contestar o que já está estabelecido no ser, [...] para além do que já é dado, um novo horizonte não dado (LAZZARATO, 2006, p. 19).

Assim, ao contestar o que está dado, os estudantes apontam que escola e currículo são dois personagens que no plano de imanência, buscam em suas lutas e desejos a "formação do ethos, do bios, da existência "militante" [...] (LAZZARATO, 2014, p. 209), indagando sobre "as formas de acesso à verdade que serão capazes de formar esse ethos, e também [sobre] as estruturas políticas no interior das quais esse ethos será capaz de afirmar a sua singularidade e diferença" (LAZZARATO, 2014, p. 213). 


\section{REFERÊNCIAS}

AGAMBEN, Giorgio. Meios sem fim: notas sobre a política. Trad.: Davi Pessoa Carneiro. Belo Horizonte: Autêntica Editora, 2015.

BERGSON, Henri. Matéria e memória: ensaio sobre a relação do corpo com o espírito. Trad.: Paulo Neves. 3. ed. São Paulo: Martins Fontes, 2006.

DAYRELL, Juarez. A escola "faz" as juventudes? Reflexões em torno da socialização juvenil. In: Educ. Soc., Campinas, vol. 28, n. 100, Especial, p. 1105-1128, out. 2007. Disponível em: 〈http://www.cedes.unicamp.br〉. Acesso em: 18 out. 2018

DELEUZE, Gilles. Imagem-Tempo. 1985. Trad.: Eloisa de Araújo Ribeiro. Brasiliense, 2007.

FERREIRA, Eliza B.; SILVA, Mônica R. Centralidade do ensino médio no contexto da nova “ordem e progresso". In: Educ. Soc. Campinas, v. 38, n. 139, abr.-jun. 2017. Disponível em: <http://www.scielo.br/pdf/es/v38n139/1678-4626es-38-139-00287.pdf>. Acesso em: 18 out. 2018.

LAZZARATO, Maurizio. Signos, máquinas, subjetividades. Trad.: Paulo Domenech Oneto com a colaboração de Hortência Lencastre. São Paulo : Edições Sesc, 2014.

. As revoluções do capitalismo. Trad.: Leonora Corsini. Rio de Janeiro: Civilização Brasileira, 2006.

PENNA, Fernando. Sobre o ódio ao professor. In: MOVIMENTO - Revista de educação. Universidade Federal Fluminense, ano 2, n. 3, 2015. Disponível em: <http://www.revistamovimento.uff.br>. Acesso em: 26 nov. 2018. 


\section{RESUMO}

O presente artigo problematiza movimentos de dogmatização do currículo e das linhas 'parresiastas' dos estudantes brasileiros, que impulsionam a questionar de quem é o currículo. Debate sobre os conceitos de 'Polícia soberana' e 'sociedade do espetáculo' (AGAMBEN, 2015), e 'sujeição social e servidão maquínica' (LAZZARATO, 2014). Assume como metodologia o acompanhamento cartográfico dos processos políticos produzidos em escolas públicas de Ensino Médio do Estado do Espírito Santo durante a Primavera Secundarista. Como procedimentos utiliza as imagens locais e nacionais divulgadas pela imprensa e as enunciações dos estudantes resistentes à reforma do Ensino Médio no Espírito Santo. Conclui que os estudantes apontam que a escola e o currículo buscam em suas lutas e desejos a formação da existência "militante", indagando as estruturas políticas no interior das quais será capaz de afirmar a sua singularidade e a diferença.

Palavras-chave: Currículo. Ensino Médio. Parresía

\section{WHOSE CURRICULUM IS IT? PROBLEMATIZATIONS OF NON-SOVEREIGN EDUCATION}

\section{SUMMARY}

The present article problematizes sovereign movements of curriculum dogmatization and the parrhesiastic statements of Brazilian students, which impel to question whose curriculum is it? It debates on the concepts of 'Sovereign police' and 'society of the spectacle' (AGAMBEN, 2015), and 'social subjection and machinic servitude' (LAZZARATO, 2014). To do so, it assumes as a methodology the cartographic monitoring of the political processes produced in public high schools in the State of Espírito Santo during the secondary spring. As methodological procedures uses the local and national images published by the press and the enunciations of students resistant to high school reform in Espírito Santo He concludes by stating that in contesting what is given, students point out that school and curriculum seek in their struggles and desires the formation of "militant" existence, inquiring about the political structures within which will be able to affirm its uniqueness and difference.

Keywords: Curriculum. High school. Parrhesía.

\section{¿QUÉ ES EL CURRICULUM? PROBLEMATIZACIONES POR UNA EDUCACIÓN NO SOBERANA}

\section{RESUMEN}

El presente artículo objetiva problematizar movimientos soberanos de dogmatización del currículo y de las líneas 'parresiastas' de los estudiantes brasileños, que impulsan a cuestionar de quién es el currículo? Debate sobre los conceptos de 'Policía soberana' y 'sociedad del espectáculo' (AGAMBEN, 2015), y 'sujeción social y servidumbre maquínica' (LAZZARATO, 2014). Para ello, asume como metodología el acompañamiento cartográfico de los procesos políticos producidos en escuelas públicas de Enseñanza Media del Estado del Espírito Santo durante la primavera secundaria. Como procedimientos metodológicos utiliza las imágenes locales y nacionales divulgadas por la prensa y las enunciaciones de los estudiantes resistentes a la reforma de la Enseñanza Media en Espírito Santo. Concluye afirmando que al contestar lo que está dado, los estudiantes apuntan que la escuela y el currículo buscan en sus luchas y deseos la formación de la existencia "militante", indagando sobre las estructuras políticas dentro de las cuales será capaz de afirmar su singularidad y la diferencia. ".

Palabras clave: Currículo. Escuela secundaria.. Parresía. 